\title{
Variants of structures of the ship's electromotive complex with common dc bus-bars
}

\author{
Fedor Gelver ${ }^{1}$ and Alecsandr Saushev ${ }^{1, *}$ \\ ${ }^{1}$ Admiral Makarov State University of Maritime and Inland Shipping, Dvinskaya Str., 5/7, Saint \\ Petersburg, 198035, Russia
}

\begin{abstract}
Schematic and algorithmic solutions for the design and construction of ship's electromotive systems of various purposes are considered. The analysis of the existing structures of electromotive complexes, as well as the types of electrical converters used is carried out. The structure of an electromotive complex based on a transformerless structure with common DC bus-bars is proposed. The main goals of improvement are to increase energy efficiency, reliability and survivability of an electric power plant, and lower weight and size characteristics. The proposed structure of the ship's electromotive complex allows braking the propellers without using additional braking circuits with the redistribution of energy between the propeller electric machines and the dissipation of braking energy in the working medium - water. An algorithm is proposed and mathematical modeling of braking and reverse modes of a propeller electric installation is carried out. Timing diagrams of changes in torque, rotation speed and power on each of the propellers for the proposed algorithm of braking and reverse of propeller motors are presented. It is shown that the synthesized structure of the electromotive complex makes it possible to reduce the emissions of pollutants into the environment, as well as to save fuel within the range of $10 \div 15 \%$, depending on the operating modes of the ship in comparison with the existing structures of the electromotive systems.
\end{abstract}

\section{Introduction}

Currently, the construction of a number of unique ships and vessels continues in Russia $[1,2]$. Most of them are special-purpose ships and vessels requiring high dynamic and operational characteristics. As a rule, electromotive systems are used as the propulsion systems that are able to fully satisfy these requirements.

Analysis of sources [2-5] shows that in practice various variations of the structures of electromotive systems are used, however, almost all projects of electromotive systems of domestic and foreign production have a sequential structure: generator - switchgear matching transformer - two-link frequency converter and propeller motor. As a rule, power crushing in such a structure of an electromotive complex is performed using several

\footnotetext{
*Corresponding author: saushevav@gumrf.ru
} 
propellers, each of which drives its own propeller motor, which is usually made in a twoarmature design. Two-link frequency converters based on two-level or three-level voltage inverters are used as electrical converters. To match the voltage levels of the generator set and the propeller motor, matching transformers installed in the electric power channel and designed for the full power of the connected electrical converter are used. Despite the widespread use and experience of using such a scheme and structure, it has a number of significant disadvantages. The main ones include: bulkiness, large mass, the presence of numerous complex and expensive electrical equipment. Many problems arise when coordinating and debugging such systems directly on ships and vessels. According to the studies carried out, the most demanded power range of a single electric drive for various types of ships is shown in Fig. 1.

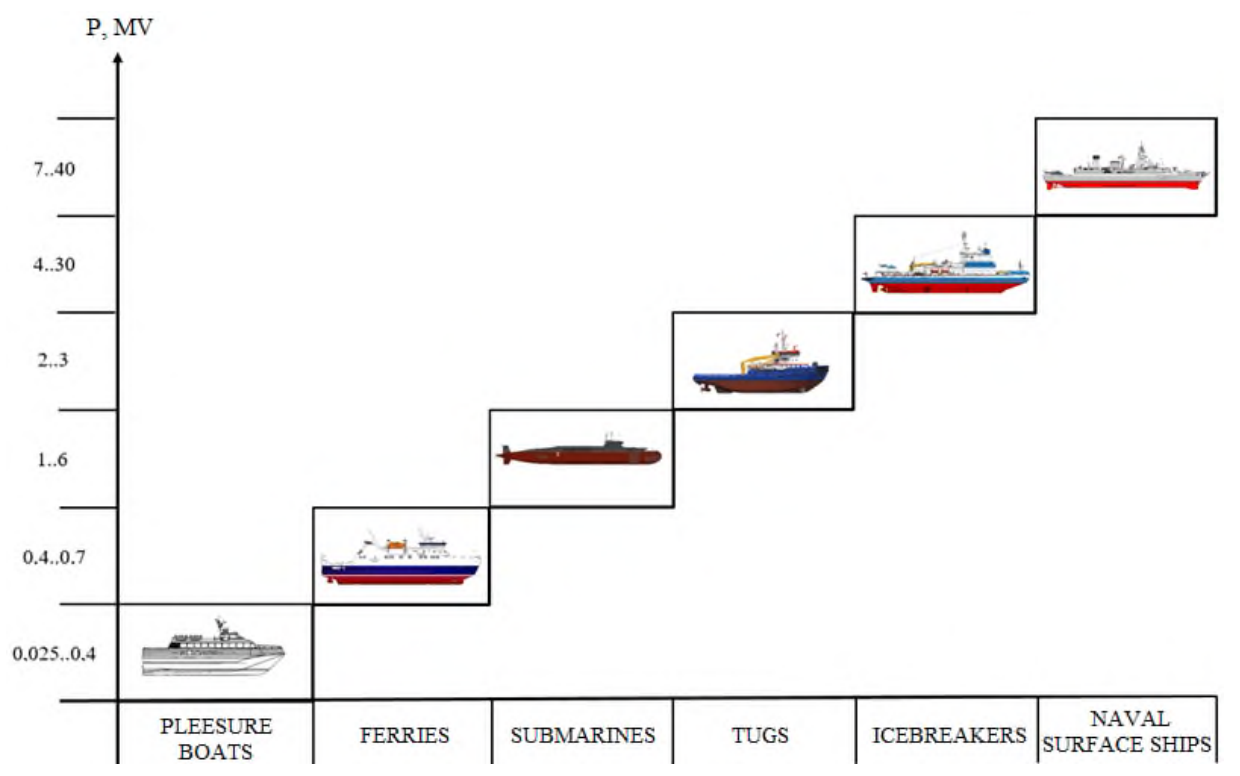

Fig. 1. The most demanded power range of a single electric drive for various types of ships and vessels.

When developing, designing and creating an electromotive complex for high-power ships with an installed power of a single electric drive of more than $5 \mathrm{MW}$, there are problems with the feasibility of such systems on the existing element base [6]. At the same time, most of the ships currently being designed and produced have an installed capacity of a single electric drive of the order of $2 \div 3 \mathrm{MW}$. Such an installed power of the electrical converter can be realized on widely used and proven in practice electronic semiconductor elements, including the element base of domestic production.

The aim of the work is to consider an approach to the synthesis of the structure of an electromotive complex, which allows for the integrated design of electrical equipment that provides an increase in the functional, operational and energy indicators of the ship. In addition, the proposed scheme and structure of the ship's electromotive complex is distinguished by simplicity, unification of the equipment used, and a high degree of reliability.

\section{Methods and Materials}

When designing ships, the unit installed power of the electric drive of which is not more than $5 \mathrm{MW}$, an integrated approach is proposed for designing the entire electromotive 
complex with a minimum number of matching and distribution elements. According to the analysis performed [2-5], the composition of the main electrical equipment of the most common structure of the electromotive complex consists of four generator sets and two propellers. A variant of constructing the structure of an electromotive complex with common DC bus-bars is presented in Fig. 2. It contains generator sets, voltage rectifiers, two-level voltage inverters, and propulsion motors.

Let us consider the main advantages of such a structure in comparison with the known structures of electromotive complexes. The proposed structure contains generator sets assembled on the basis of a primary heat engine E and an electric AC generator G, each of which operates on its own voltage rectifier R. Generating sets are grouped along the boards, while the voltage rectifiers R1 and R2 (R3 and R4) are of one board are connected in series in a coordinated manner with their output terminals and organize a common system of DC bus-bars on one board. Two-level voltage inverters I1 $\div \mathrm{I} 4$ are connected to the common DC bus-bar system of each of the boards of the power plant, which feed the propulsion motors $\mathrm{M} 1 \div \mathrm{M} 4$. Propulsion motors M1, M3 and M2, M4 constitute drives for the first and second propeller, respectively, and the propeller motors M1 and M3 (M2 and M4) work in concert together, creating either a driving or braking torque. It should be noted that, if necessary, one of the two motors of one propeller can operate in the fractional modes of operation of the ship. The power supply for the propulsion motors $\mathrm{M} 1 \div \mathrm{M} 4$ is organized in such a way that each of the propellers can be driven by the energy received from the power plant of any board and even from any one of the operating generating sets. This structure organizes a double DC bus-bar electric propulsion system. At the same time, power plants and electrical equipment on different boards are galvanically isolated.

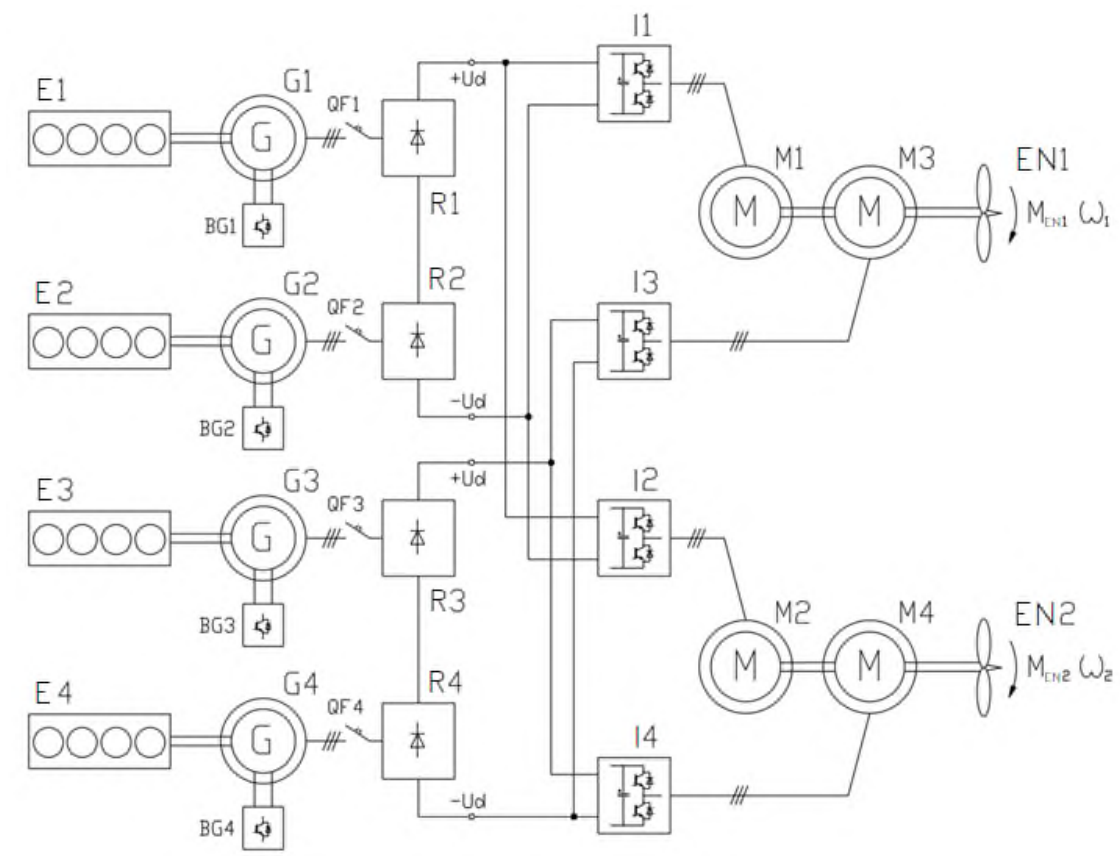

Fig. 2. Block diagram of the ship's electromotive complex with double DC bus-bars based on twolevel voltage inverters.

The electric generator $\mathrm{G}$ can be implemented on widely used synchronous generators with an electromagnetic excitation system. Shown in Fig. 2, the electric generator G contains an excitation winding with its own excitation system $\mathrm{BG}$, which makes it possible 
to regulate the voltage level at its output without time delays. This solution allows to quickly change the voltage level on the common DC bus-bar system of the corresponding board in a stationary mode of operation, as well as to ensure a smooth charge of the storage capacitors of the inverters I without using various soft starters. Any diesel engines, gas turbine engines can be used as the primary heat engine of the generator set in the structure under consideration without limiting their rotation speed. At the same time, the primary heat engine can operate at the optimum rotation speed for itself, providing high efficiency $[7,8]$. The voltage rectifiers R1 and R2 (R3 and R4) of the AC generators G1 and G2 (G3 and G4) of one board are connected in series in a coordinated manner and form a common system of DC bus-bars of one board. Such a connection of rectifiers R makes it possible to double the voltage of the DC bus-bars of one board at the same voltages of electric generators G. In addition, such a circuit design allows one of the two generator sets of the power plant on one board to be used during operation of the electromotive complex, while the second generator set can be taken out of operation. The propeller motors M1, M3 (M2, M4) of one propeller are powered through voltage inverters I1, I3 (I2, I4) connected to different onboard DC bus-bar systems (to power plants on different boards). It should be noted that the DC bus-bars of the two boards are galvanically isolated and have absolutely no electrical connection with each other, which makes it possible to ensure stable electromagnetic compatibility, high reliability and survivability of the propulsion electric installation. The proposed circuit solution allows to maintain the operational state of the propulsion electric installation even with one operating generator set. This structure has a high degree of efficiency and provides a long service life of primary heat engines due to the fact that the optimal mode of their operation, corresponding speed of the ship, the degree of their load are guaranteed. It excludes underloading of generating sets in terms of power or their idle operation, there is no need for precise synchronization of generating sets, as well as problems with their input and output from operation.

\section{Results}

Let us consider the operating modes of the power plant and the possibilities of the proposed structure of the ship's electromotive complex, shown in Fig. 2. For a stationary mode of ship movement, according to the ventilatory nature of the propeller load, the dependence $\mathrm{N}=\mathrm{f}(\mathrm{V})$ can be constructed, which characterizes the power $(\mathrm{N})$ of the propeller electric installation, depending on the speed of the ship (V). Fig. 3 shows the dependence $N=f(V)$, given in relative units for the stationary mode of the propulsion electric installation when the ship is moving in free water. 


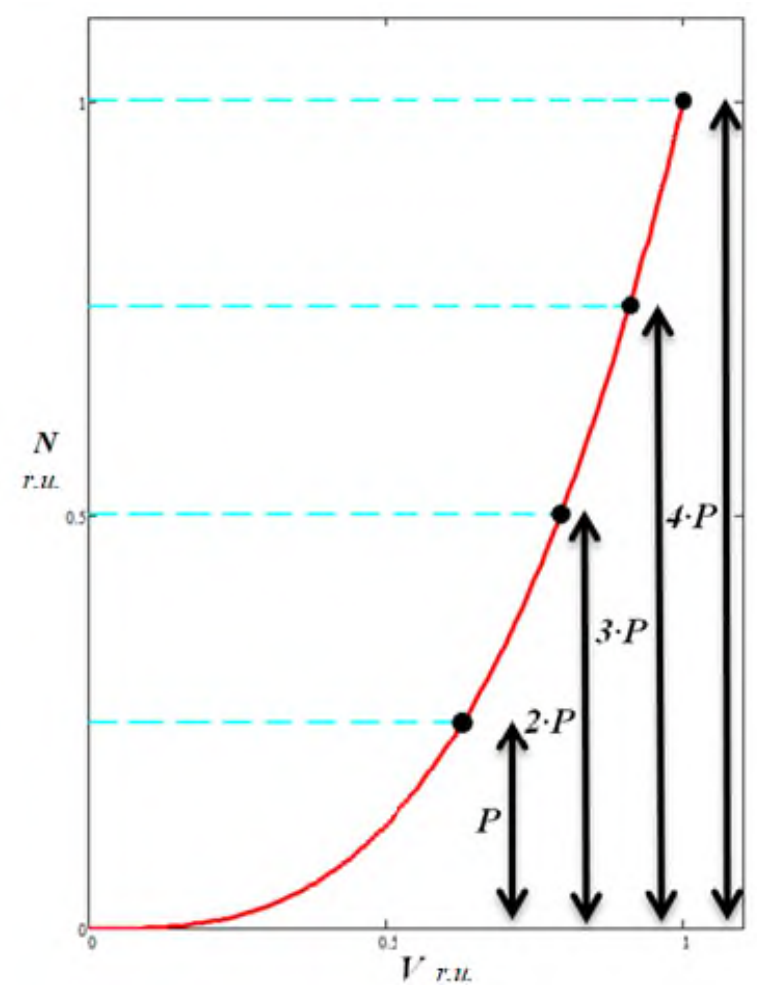

Fig. 3. Dependence $\mathrm{N}=\mathrm{f}(\mathrm{V})$ for the stationary mode of the propulsion electric installation when the ship is moving in free water.

Based on the given dependence for the structure under consideration (Fig. 2), the relationship between the required number of operating generating sets as a function of the required ship speed can be obtained. Table 1 shows such a dependence for a propeller electric installation consisting of four generator sets of the same type, the installed power of each of which is equal to $P$.

Table 1. Dependence of the required number of operating generating sets from the current speed of the ship.

\begin{tabular}{|c|c|c|}
\hline $\begin{array}{c}\text { Number of operating } \\
\text { generating sets }\end{array}$ & $\begin{array}{c}\text { Maximum power of the } \\
\text { power plant P relative unit }\end{array}$ & $\begin{array}{c}\text { The movement of the ship at } \\
\text { a speed of V relative unit }\end{array}$ \\
\hline 1 & 0.25 & $0 . .0 .63$ \\
\hline 2 & 0.5 & $0.63 . .0 .79$ \\
\hline 3 & 0.75 & $0.79 . .0 .9$ \\
\hline 4 & 1 & $0.9 . .1$ \\
\hline
\end{tabular}

From the graph (Fig. 3) and Table 1 it can be seen that for the fractional operating modes of the propeller electric installation, any number of the installed generating sets can be used, which will provide the required power and speed of the ship. At the same time, for uniform use of generating sets in terms of operating time, they can be changed and combined in any conjunction. The undoubted advantage of the proposed structure of the propulsion complex is its versatility, which allows using any type of AC electric machine as an electromechanical converter.

An important feature of the proposed structure is the possibility of braking and reversing propeller motors without using brake circuits as part of the electrical converters of these electric motors. If it is necessary to brake the ship and reverse the propulsion electric 
motors, the braking and reverse of the latter will be carried out by redistributing energy between the propulsion motors M1, M2 and M3, M4. Fig. 4 shows the directions of energy flows during braking and reverse of the propeller drive, built according to the scheme in Fig. 2.
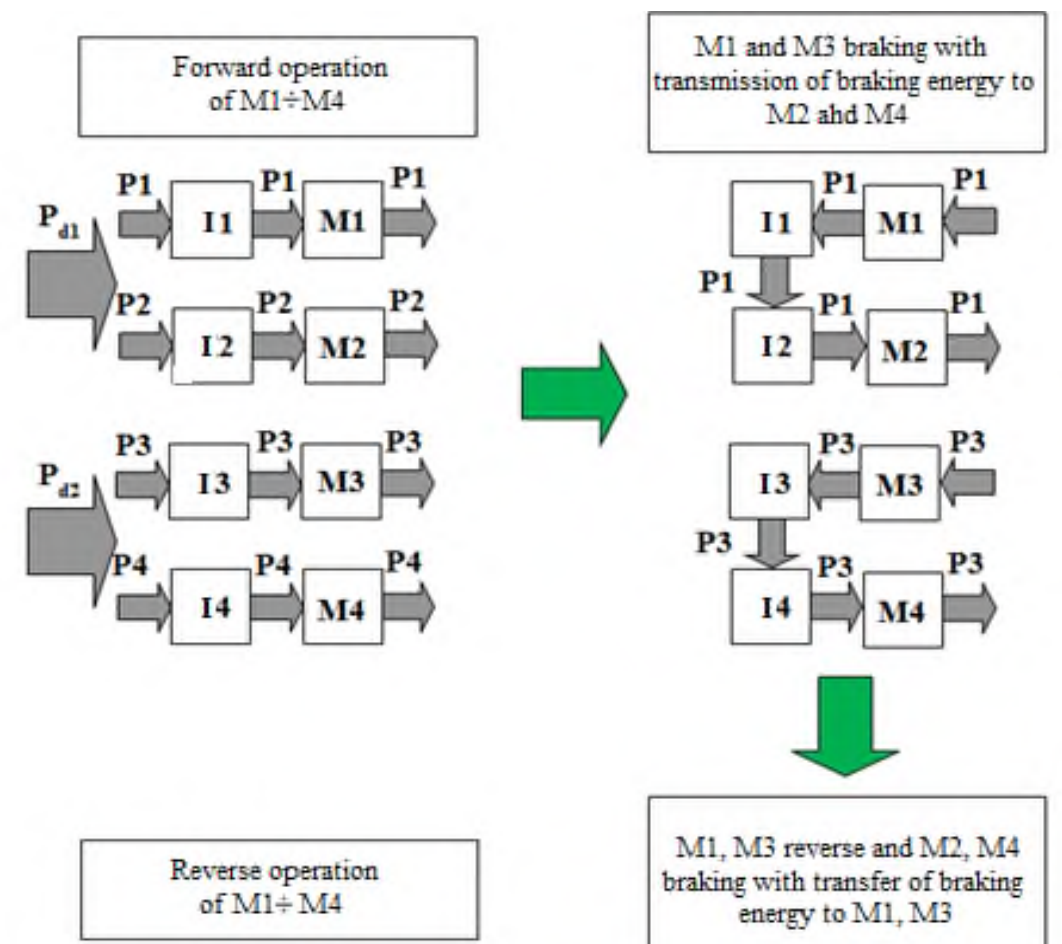

$\mathrm{M1}, \mathrm{M} 3$ reverse and $\mathrm{M} 2, \mathrm{M} 4$ braking with transfer of braking energy to $\mathrm{M1}, \mathrm{M} 3$
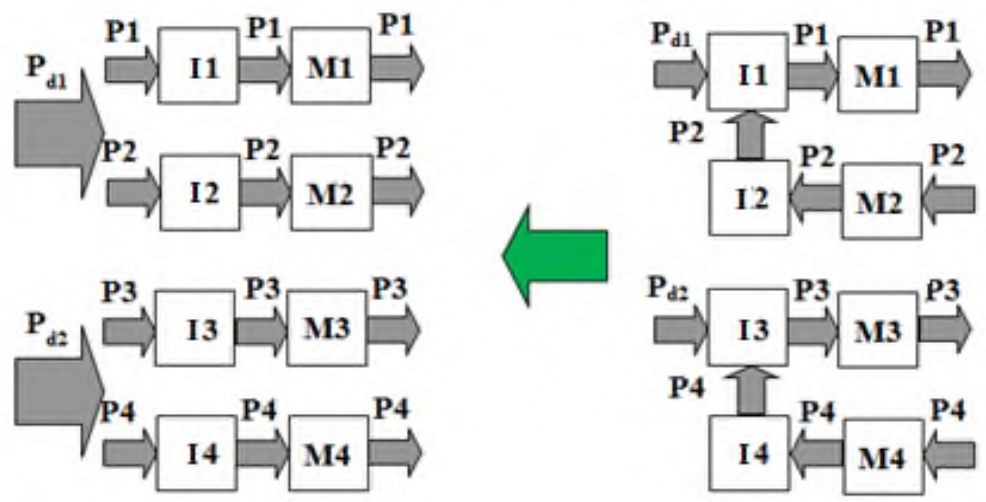

Fig. 4. Direction of power flows during braking of the propeller electric installation.

Fig. 5 and Fig. 6 show the simulation results for braking and reversing the propulsion electric installation according to the proposed algorithm. Fig. 5 shows the dependences $\omega_{1}(t), \quad M_{e n 1}(t), \omega_{2}(t), \quad M_{e n 2}(t)$, and in Fig. 6 shows dependencies $\operatorname{Pen}_{1}(t), \operatorname{Pen}_{2}(t)$, $\operatorname{Pen}_{1}(\mathrm{t})+\operatorname{Pen}_{2}(\mathrm{t})$ during braking and reverse of the propellers of the ship's electromotive complex. A more detailed mathematical description of braking and reverse of the propeller drive is given in [9]. 


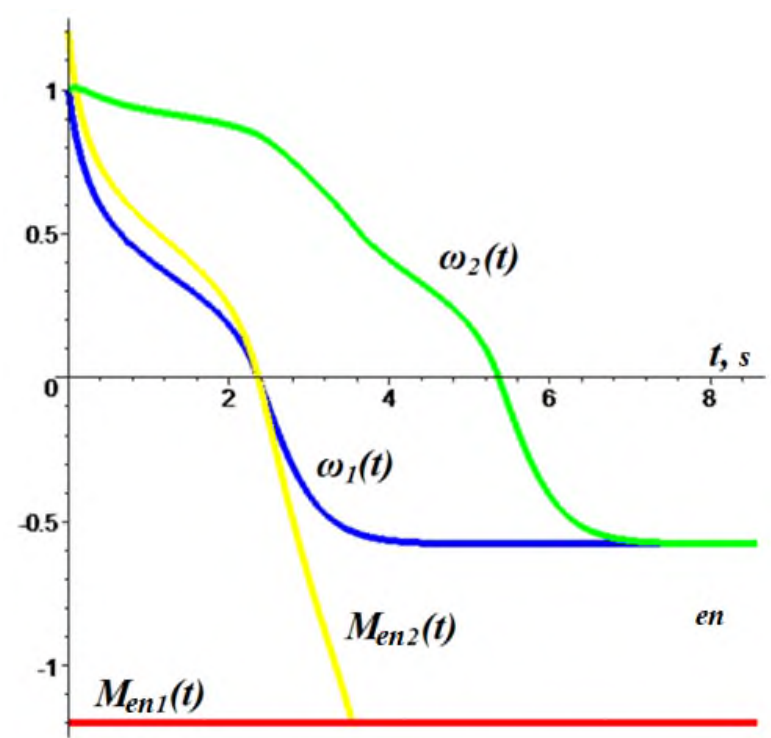

Fig. 5. Dependences $\omega_{1}(t), M_{e n 1}(t), \omega_{2}(t), M_{e n 2}(t)$ during braking and reverse of the propeller drive.

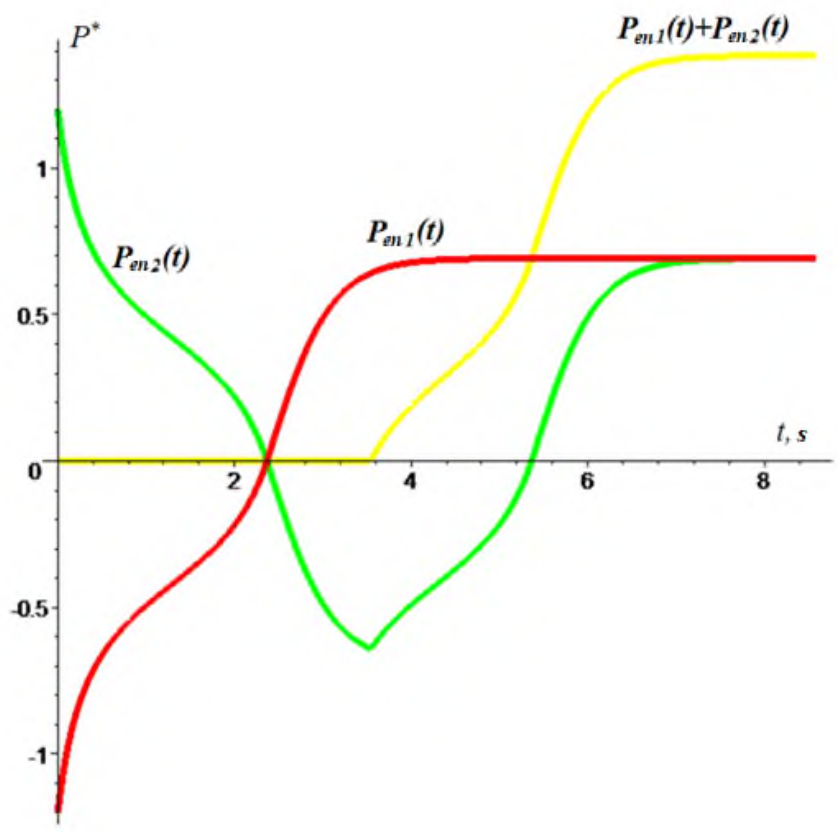

Fig. 6. Dependence of $\operatorname{Pen}_{1}(\mathrm{t}), \mathrm{Pen}_{2}(\mathrm{t}), \mathrm{Pen}_{1}(\mathrm{t})+\mathrm{Pen}_{2}(\mathrm{t})$ during propeller braking and reverse.

The considered structure of the electromotive complex (Fig. 2) has a limit on the power of a single electric drive, which is about $2 \div 3 \mathrm{MW}$ and is determined by the circuitry implementation of the voltage inverter and the range of manufactured semiconductor elements.

In order to increase the installed unit power of the electric drive of the electromotive complex, as well as to improve the quality of the synthesized voltage, reliability and survivability of the ship complex under consideration, the proposed structure (Fig. 2) can be transformed for use in conjunction with three-level voltage inverters. The structure of an 
electromotive complex based on three-level voltage inverters (Fig. 7) can be implemented using three-level voltage inverters built on the basis of a voltage inverter circuit with a zero point (Fig. $7 \mathrm{~A}$ ) or on the basis of a T-shaped voltage inverter circuit (Fig. 7 B). When using three-level voltage inverters, the zero point of the three-level voltage inverters must be connected to the common point of the rectifiers forming a DC bus-bar system of one board (Fig. 7).

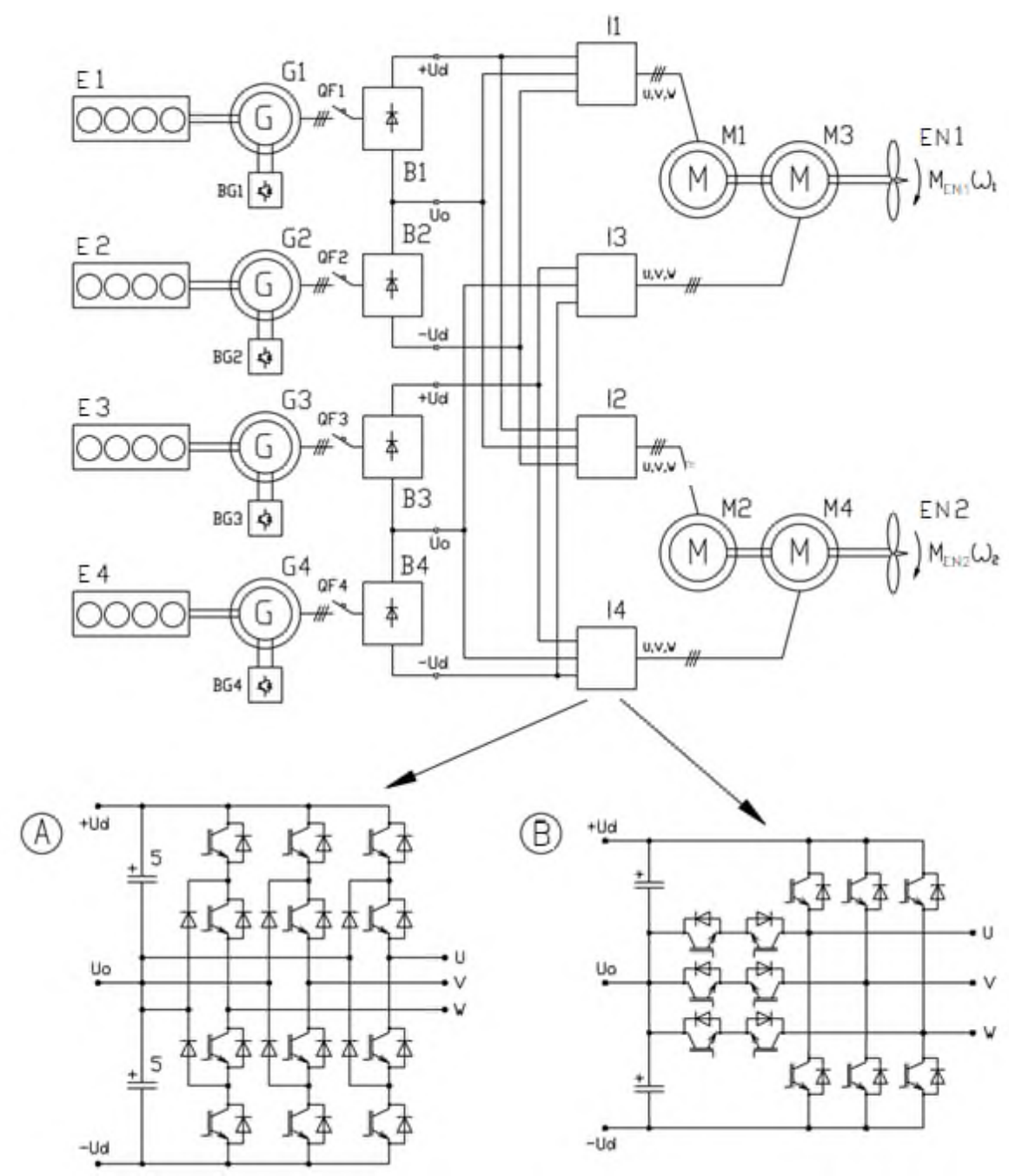

Fig. 7. Block diagram of the ship's electromotive complex with double DC bus-bars based on threelevel inverters: A - with a zero point; B - in a T-shaped scheme.

A huge advantage of the proposed version of the electromotive complex circuit based on three-level voltage inverters is high reliability, as well as the ability to operate propellers from just any one generator set. In this case, the three-level voltage inverter will operate in the two-level inverter mode. The power limit for a single electric drive in such a structure on the existing element base is about $5 \mathrm{MW}$. 


\section{Discussion}

The considered structures of the ship's electromotive complex (Fig. 2) and (Fig. 7) are universal and can be easily transformed for new power sources, for example, electrochemical generators, storage batteries, etc. The use of the proposed circuits of the electromotive complex (Fig. 2) and (Fig. 7) with double DC bus-bars makes it possible to exclude the occurrence of an emergency situation in which the failure of any of the elements will lead to the failure of the entire electromotive complex. This ensures high reliability and stable electromagnetic compatibility during operation of the power plant on different boards.

If it is necessary to implement a unified electric power system, such structures can be equipped with a voltage inverter and a matching transformer that provides power to consumers for their own needs. In this case, the voltage inverter receives power from the common bus-bars of the DC link and is loaded onto the primary winding of the transformer, the secondary winding of which supplies power to the consumers of their own needs.

If an electric energy storage device with a matching electrical converter is connected to the DC bus-bar system, then it becomes possible to accumulate energy when braking propeller motors with the subsequent expenditure of this energy for accelerating the propulsion motors. At the same time, the energy efficiency and economy of the ship's power plant are significantly increased. In addition, such a circuit design will make it possible to bring the total installed power of the propulsion motors as close as possible to the established power of the generating sets. The dynamics in such a system will be covered exclusively by the storage of electrical energy.

To further increase the established power of a single electric drive of the electromotive complex with restrictions imposed on the number of propellers and propeller motors, a propeller electric installation based on a cascade frequency converter can be proposed [10, 11]. A cascade frequency converter is capable of realizing an electrical converter of practically unlimited power with restrictions imposed on the parameters of the semiconductor elements used.

\section{Conclusion}

The proposed structures of the ship's electromotive complex are distinguished by their versatility, simplicity of circuit implementation and make it possible to increase its reliability and survivability. The main advantage of the proposed structures in comparison with the existing structures of electromotive complexes of ships is the exclusion of a bulky and massive matching transformer, as well as brake circuits of frequency converters. Any type of AC electric machine can be used as an electromechanical converter in such a structure. An important factor is the high environmental compatibility and a small amount of polluting emissions into the environment of such a power plant due to the fact that the primary heat engines operate in an optimal mode, and the voltage inverters are able to redistribute energy flows among themselves, optimizing the energy consumption criterion.

The considered structures can be implemented with a different number of generator sets and propeller motors, based on the required characteristics and power of the electromotive complex. The proposed structure makes it possible to reduce the number of transformations of electrical energy, as well as to simplify the units and elements of energy distribution on the ship, to increase the energy efficiency indicator, to brake and reverse electric drives (braking the ship) without using brake circuits. High-speed primary heat engines can be used as generator sets in such structures, and voltage inverters for propulsion motors can be built on the basis of three-level voltage inverters, which allow obtaining high quality synthesized voltage for powering propulsion motors. 


\section{References}

1. S.S. Poloskov, Voprosy innovatsionnoy ekonomiki 8(3), 465-478 (2018) https://doi.org/10.18334/vinec.8.3.39404

2. V. Vershinin, S. Makhonin, V. Parshikov, V. Khomyak, Transactions of the Krylov State Research Centre 1(387), 107-122 (2019) https://doi.org/10.24937/2542-23242019-1-387-107-122

3. E. Koptyaev, E. Popkov, Elektrichestvo 2(2), 33-39 (2019) https://doi.org/10.24160/0013-5380-2019-2-33-39

4. V.V. Romanovsky, B.V. Nikiforov, A.M. Makarov, Vestnik Gosudarstvennogo universiteta morskogo i rechnogo flota imeni admirala S.O. Makarova 10.3, 586-596 (2018) https://doi.org/10.21821/2309-5180-2018-10-3-586-596

5. A.V. Grigoryev, A.Yu. Vasilyev, R.R. Zaynullin, Vestnik Gosudarstvennogo universiteta morskogo i rechnogo flota imeni admirala S.O. Makarova 10.1, 229-237 (2018) https://doi.org/ 10.21821/2309-5180-2018-10-1-229-237

6. F. Gelver, I. Belousov, V. Samoseiko, Bulletin of Perm National Research Polytechnic University. Electrotechnics, Informational Technologies, Control Systems 30, 7-27 (2019) https://doi.org/10.15593/2224-9397/2019.2.01

7. A.N. Gots, V.F. Guskov, A.M. Temnov, Modern high technologies 6-2, 234-240 (2020) https://doi.org/10.17513/snt.38098

8. A. Chernov, A. Akimov, Izvestiya MGTU MAMI 40(2), 88-96 (2019) https://doi.org/10.31992/2074-0530-2019-40-2-88-96

9. F. Gelver, V. Samoseiko, A. Saushev, E3S Web of Conferences 135, 02009 (2019) https://doi.org/10.1051/e3sconf/201913502009

10. F. Gelver, A. Saushev, D. Semenov, EMMFT-2018 Advances in Intelligent Systems and Computing 982 (2018) https://doi.org/10.1007/978-3-030-19756-8_44

11. F. Gelver, I. Belousov A. Saushev, EMMFT 2019. Advances in Intelligent Systems and Computing 1258 (2019) https://doi.org/10.1007/978-3-030-57450-5_32 